\title{
Erratum to: A resting-state functional MRI study on central control of storage: brain response provoked by strong desire to void
}

\author{
Yi Gao ${ }^{1,2,3} \cdot$ Limin Liao $^{1,2,3}$ • Bertil F. M. Blok ${ }^{4}$
}

Published online: 18 July 2015

(C) Springer Science+Business Media Dordrecht 2015

\section{Erratum to: Int Urol Nephrol (2015) 47:927-935 \\ DOI 10.1007/s11255-015-0978-0}

In the original publication, the second affiliation has been published with an error, and the first two affiliations should be swapped. The corrected and reordered first two affiliations are given below:

${ }^{1}$ School of Rehabilitation Medicine, Capital Medical University, Beijing, China.

${ }^{2}$ Department of Urology, China Rehabilitation Research Centre, No 10. Jiaomen Beilu, Fengtai District, Beijing 100068, China.

The online version of the original article can be found under doi:10.1007/s11255-015-0978-0.

Limin Liao

lmliao@263.net

1 School of Rehabilitation Medicine, Capital Medical University, Beijing, China

2 Department of Urology, China Rehabilitation Research Centre, No 10. Jiaomen Beilu, Fengtai District, Beijing 100068, China

3 Center of Neural Injury and Repair, Beijing Institute for Brain Disorders, Beijing, China

4 Department of Urology, Erasmus Medical Center, Rotterdam, The Netherlands 